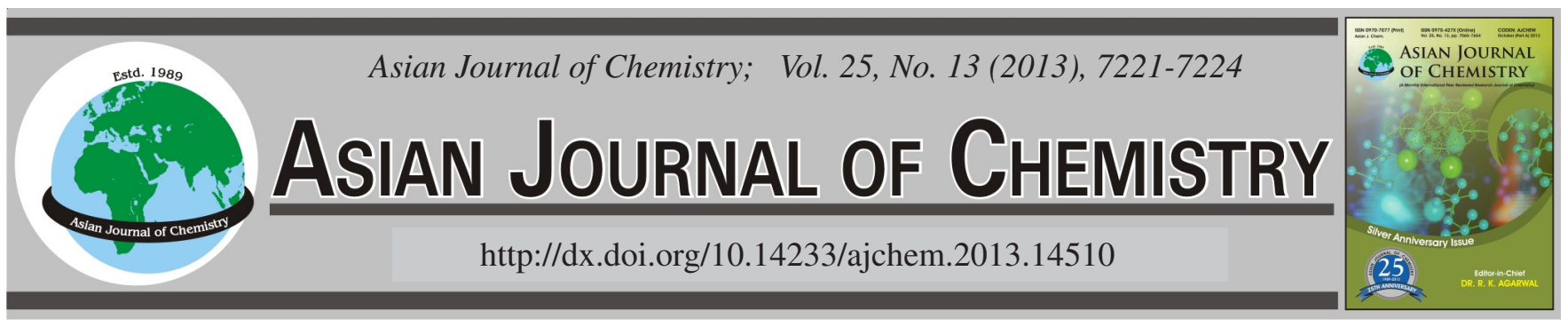

\title{
Flexural Properties and Fracture Mechanism of Three-Dimensional and Four-Directional Braided $\left(\mathrm{SiO}_{2}\right)_{\mathrm{f}} / \mathrm{SiO}_{2}$ Composites
}

\author{
Binbin Li ${ }^{1,2, *}$, JiAnXun Zhu ${ }^{1,2}$, ZhaOfeng Chen $^{1}$, Yun JiAng $^{2}$ and Fangtian Hu ${ }^{2}$
}

\begin{abstract}
${ }^{1}$ College of Material Science and Technology, Nanjing University of Aeronautics and Astronautics, Nanjing 210016, P.R. China
\end{abstract} ${ }^{2}$ Sinamo Science and Technology Company Limited, Nanjing 210013, P.R. China

*Corresponding author: Tel: +86 25 52112909; E-mai: lidahai12@gmail.com; bbli@nuaa.edu.cn

(Received: 1 September 2012;

Accepted: 19 June 2013)

AJC-13677

\begin{abstract}
Three-dimensional and four-directional braided $\left(\mathrm{SiO}_{2}\right)_{\mathrm{f}} / \mathrm{SiO}_{2}$ composites were prepared by silicasol-infiltration-sintering method. The specimen density was determined to be $1.71 \mathrm{~g} / \mathrm{cm}^{3}$ by using the Archimedes principle. The flexural properties were evaluated by threepoint bending test. The flexural strength and flexural elastic modulus were found to be $62 \mathrm{MPa}$ and $11 \mathrm{GPa}$, respectively. The stress $v s$. deflection curve showed a typical composite behaviour, initially a linear elastic response, followed a nonlinear region and finally failed gracefully. The SEM micrograph of the fracture sections showed extensive fibers pull-out, indicating the composites exhibited good toughness. A distinctly crevice was observed along the interfacial region, indicating the weak interfacial bonding between fiber and matrix, resulting in extensive fibers pull-out with a failure strain. The results of stress $v s$. deflection and SEM examination revealed that the fracture mechanism of the $\left(\mathrm{SiO}_{2}\right)_{\mathrm{f}} / \mathrm{SiO}_{2}$ composite was a mixed mode of brittle and ductile.
\end{abstract}

Key Words: Three-dimensional and four-directional, $\left(\mathrm{SiO}_{2}\right)_{\mathrm{f}} / \mathrm{SiO}_{2}$ composites, Silica sol-infiltration-sintering process, Flexural properties, Fracture mechanism.

\section{INTRODUCTION}

Silica is an important ceramic material with low thermalconductivity, thermal expansion and excellent thermal-shock resistance, which makes it as one of the most promising materials for Radome applications ${ }^{1,2}$. However, low flexural strength and low fracture toughness have restrained its further applications. For the purpose of improving the mechanical properties, silica fiber is considered as one of most attractive candidate reinforcement for the $\mathrm{SiO}_{2}$ matrix. Many efforts ${ }^{3-9}$ have been made to reinforce $\mathrm{SiO}_{2}$ matrix composites by adding shorter silica fiber, long silica fiber, 2.5 D silica braided and conventional 3D silica braided reinforcement. Meyer et al. ${ }^{3}$ have reported short-chopped silica fiber reinforced $\mathrm{SiO}_{2}$ composite by pressureless sintering method. Glass and silica fiber reinforced silica matrix foams have been developed through slurry based processing, which are beneficial to increase the stiffness of the composite foam ${ }^{4}$. Unidirectional silica fiber reinforced $\mathrm{SiO}_{2}$ composite were prepared by pressureless sintering and hot pressing method and it was concluded that the promoted mechanical properties were attributed to the pull-out of the fiber ${ }^{5}$. $2.5 \mathrm{D}\left(\mathrm{SiO}_{2}\right)_{\mathrm{f}} / \mathrm{SiO}_{2}$ composites were fabricated via sol gel infiltration method and the flexural strength of the composites varied from $31-80 \mathrm{MPa}^{6}$. It can be inferred that the mechanical properties of $\left(\mathrm{SiO}_{2}\right)_{\mathrm{f}} / \mathrm{SiO}_{2}$ composites are closely related to the braided structure of reinforcement and the preparation method ${ }^{10}$. However, a few literatures have reported on $3 \mathrm{D}$ four-directional braided $\left(\mathrm{SiO}_{2}\right)_{\mathrm{f}} / \mathrm{SiO}_{2}$ composites, which have a number of advantages over the conventional $3 \mathrm{D}$ composites, including better out-of-plane stiffness, strength and high damage tolerance ${ }^{11}$.

In this paper, the preparation and processing details as well as flexural properties (strength and modulus) and mode of fracture of 3D four-directional braided $\left(\mathrm{SiO}_{2}\right)_{\mathrm{f}} / \mathrm{SiO}_{2}$ composites are reported and discussed.

\section{EXPERIMENTAL}

Composites preparation: The 3D four-directional braided silica reinforcements were provided by Sinamo Science and Technology Company Limited, Nanjing, China. The yarn specification was B type silica fiber (190Tex) and the fiber volume fraction was $c a .47 \%$. Fig. 1(a) shows the representative unit and overall morphology of 3D four-directional braided silica structure, respectively.

The $\left(\mathrm{SiO}_{2}\right)_{\mathrm{f}} / \mathrm{SiO}_{2}$ composites were fabricated by Silica SolInfiltration-Sintering method (Fig. 2). Firstly, the 3D fourdirectional braided silica reinforcements were placed in a closed container and the container was evacuated to $0.1 \mathrm{~Pa}$. Then, the high pure silica sol (volume ratio $35 \%$, average 

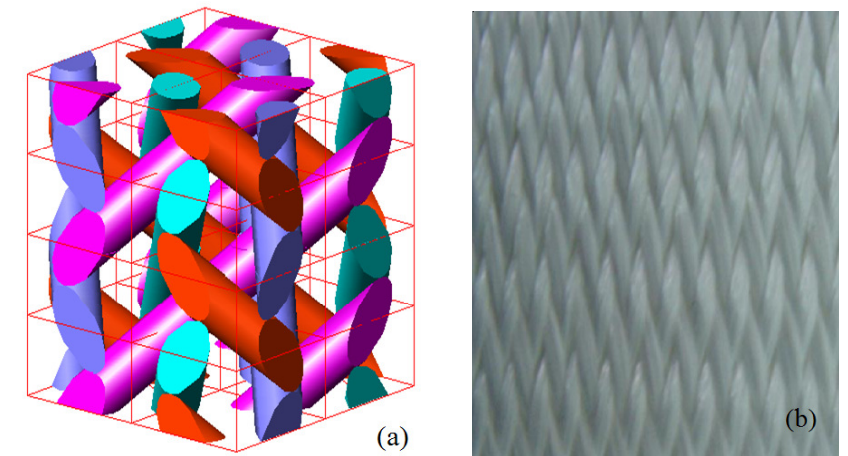

Fig. 1. 3D and four-directional braided silica structure: (a) single unit; (b) overall morphology

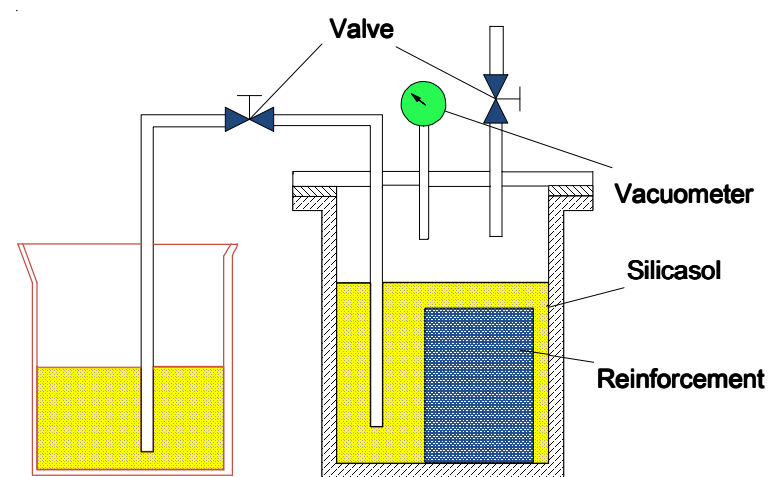

Fig. 2. Schematic diagram of silicasol-infiltration method

particle size $10 \mathrm{~nm}, \mathrm{pH} 9$ obtained from, Ningbo Company, China) was sucked into the container and during which entire process, the pressure was maintained at $0.1 \mathrm{~Pa}$. The container was then pressurized to $10 \mathrm{~atm}$ and maintained at that high pressure for $1 \mathrm{~h}$. The composites were then dried at $80^{\circ} \mathrm{C}$ for $1 \mathrm{~h}$ and $110{ }^{\circ} \mathrm{C}$ for $1 \mathrm{~h}$ to gradually remove water content of the gel solution. Then it was sintered at $450^{\circ} \mathrm{C}$ for $2 \mathrm{~h}$ to remove the coupling agent and bounded water. The process was repeated for ten cycles to obtain the final composite.

Test specimens were cut parallel to the direction of fiber and then ground into bars of $40 \mathrm{~mm}$ in length, $5 \mathrm{~mm}$ in width and $3.5 \mathrm{~mm}$ in thickness. Three-point bend tests on an Iosipescu Universal tester (SANS CMT5105 electronic universal testing machine) were conducted with a displacement rate of $0.1 \mathrm{~mm} /$ min and $30 \mathrm{~mm}$ span according to British Standard Methods of Testing. The load vs. deflection data were recorded till fracture. The fracture strength and elastic modulus were computed from the load deflection data. Microstructure and fracture mechanism were examined by scanning electron microscopy (JEOL JSM-6360). The specimens for SEM were gold coated.

\section{RESULTS AND DISCUSSION}

The specimen density was determined using the Archimedes principle according to ASTM specification D792-00 ${ }^{12}$.

$$
\rho=\frac{m_{a}}{m_{a}+m_{p}-m_{b}}
$$

where $\rho$ is the density of the composite material, $m_{a}$ is the weight of the specimen when hung in the air, $\mathrm{m}_{\mathrm{p}}$ is the weight of the partly immersed wire holding the specimen, $\mathrm{m}_{\mathrm{b}}$ is the weight of the specimen when immersed fully in distilled water, along with the partly immersed wire holding the specimen; $\rho_{w}$ is the density of the distilled water at testing temperature. The specimen density of 3D four-directional $\left(\mathrm{SiO}_{2}\right)_{\mathrm{f}} / \mathrm{SiO}_{2}$ composite was found to be $1.71 \mathrm{~g} / \mathrm{cm}^{3}$.

Fig. 3 is stress vs. strain curve for a typical CFCC. The curve could be divided into three stages, namely: elastic, damage and failure. At the elastic stage, the mechanical behaviour of the composites is grossly linear elastic. The matrix cracks and other defects due to manufacturing do not grow to cause any significant amount of damage at this stage and the composites attains a peak or maximum stress $\left(\sigma_{\mathrm{u}}\right)$. Following this, damage in the form of a nonlinear region with increasing stress with deflection is mostly observed. During this damage stage, the matrix continuously cracks, meanwhile the interface of fiber/ matrix debonds. The matrix fails when the maxim stress is attained. At the failure stage, there are two different modes: A typical brittle/sudden fracture behaviour, with no fiber pullout and/or a typical ductile/gradual fracture behaviour, with extensive fibers or bundles pull-out.

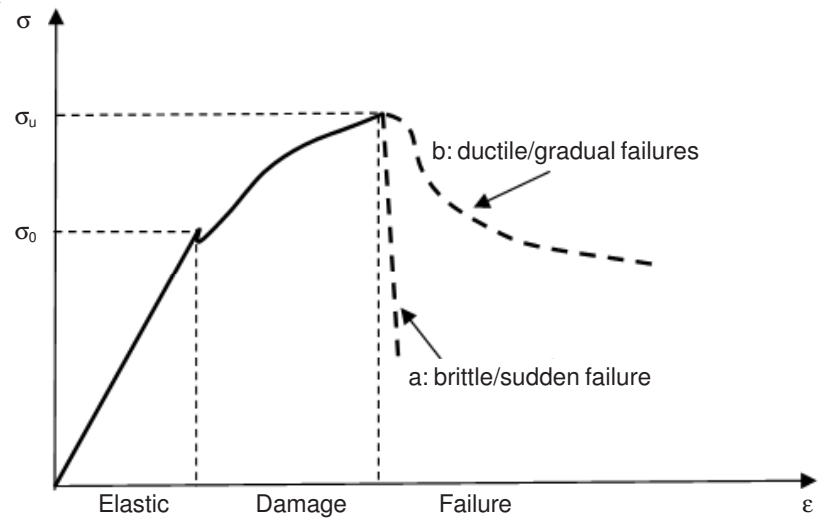

Fig. 3. Typical stress vs. strain curve of CFCCs

Fig. 4 shows the actual stress vs. deflection curve of 3D four-directional $\left(\mathrm{SiO}_{2}\right)_{\mathrm{f}} / \mathrm{SiO}_{2}$ composite. The maximum stress the composite exhibited was about $50 \mathrm{MPa}$. Fig. 5(b) shows the SEM fractographs of the initial silica matrix, presented large particles and good poly-crystallization indicating an effective SIS processing. At the damage stage, a nonlinear region, though of a limited extent is observed. The matrix failed when the maximum stress reached $62 \mathrm{MPa}$. After the attainment of maximum stress, the stress dropped suddenly, caused by fracture of the fibers, indicating the mechanism was a brittle mode. However, further stress drop was found to be gradual. Then stress dropped steadily, caused by the fibers pull-out, indicating the mechanism changed to a ductile mode. And the fibers were fractured and pulled out in turn until failure. It can be concluded that the fracture mechanism of the composite was a combination of ductile and brittle modes. The flexural strength and elastic modulus of three-point bending test was ca. $62 \mathrm{MPa}$ and $11 \mathrm{GPa}$, respectively.

In general, the microstructure was consistent with the mechanical properties. The nature of the fiber/matrix interface can be seen by examining the fracture surface of the composite specimens after the three-point bending test. The improved 


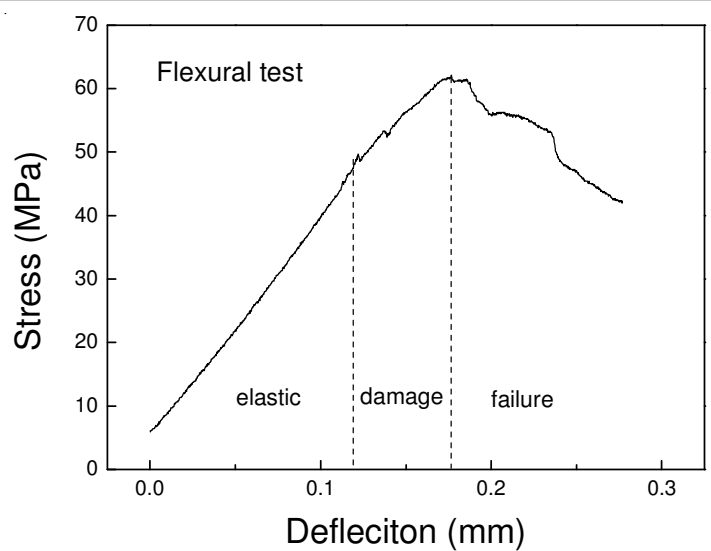

Fig. 4. Stress vs. deflection curve of $\left(\mathrm{SiO}_{2}\right)_{\mathrm{f}} / \mathrm{SiO}_{2}$ composite

toughness was obtained from a microstructure where the fibers can absorb energy of stress concentrations by bridging crack surfaces and dissipation energy as the matrix disintegrates during fibers pull-out. Fig. 5(a) is a typical SEM image of the fracture structure of the $\left(\mathrm{SiO}_{2}\right)_{\mathrm{f}} / \mathrm{SiO}_{2}$ composite, which showed extensive fibers pull-out on low magnification SEM.
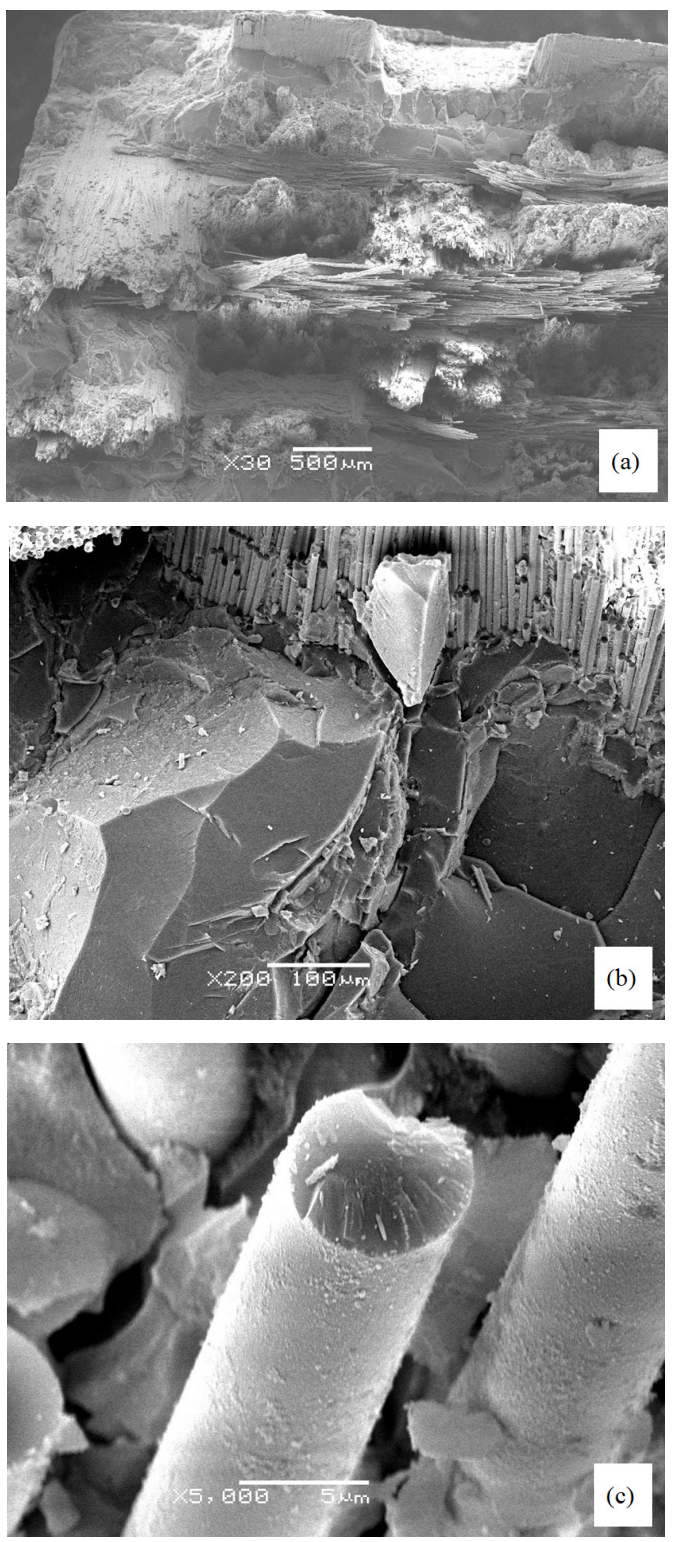

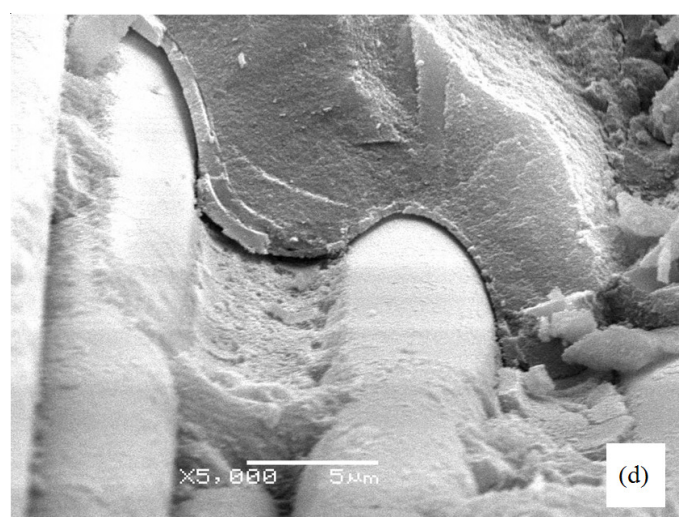

Fig. 5. SEM images of fracture section: (a) Fracture surface; (b) Silica matrix; (c) Fibers pull-out; (d) Interfacial region

The purpose of the fiber/matrix interfacial materials is to provide a proper fiber/matrix interface. The functions of the interface are (1) to prevent damage matrix cracking from penetrating the fibers; (2) to maintain a good load transfer between the fibers and the matrix; (3) to act as a diffusion barrier and relaxation of residual stress ${ }^{13}$. If the bonding strength of fiber/ matrix is weak, the fiber will be easy to pull-out, causing a good toughness and low fracture work. On the other hand, if the bonding strength of fiber/matrix is strong, the fiber will be difficult to pull-out, causing a brittle fracture and high fracture work.

The sintering temperature of the samples was maintained only at $450{ }^{\circ} \mathrm{C}$, much lower than the values suggested by previous workers ${ }^{9,11}$, because silica fiber tend to get damaged after high temperature treatment ${ }^{14}$. The bonding strength of fiber/matrix would then be weak at low temperature, causing the extensive fibers pull-out as shown in Fig. 5(a-b). Hence, the fabrication process of $\left(\mathrm{SiO}_{2}\right)_{\mathrm{f}} / \mathrm{SiO}_{2}$ composites was repeated for ten-cycle process. During these repeated cycles, micro defects or cracks of the fibers were found to accumulate, causing a fiber peeling on further increase in stress. A distinctly crevice was observed between the fiber and the matrix, as shown in Fig. 5(d).

\section{Conclusion}

Three-dimensional and four-directional braided $\left(\mathrm{SiO}_{2}\right)_{\mathrm{f}} /$ $\mathrm{SiO}_{2}$ composites were fabricated by silicasol-infiltrationsintering method. The flexural strength and Young's modulus were $62 \mathrm{MPa}$ and $11 \mathrm{GPa}$, respectively. The stress vs. deflection curve showed a typical composite behaviour, initially a linear elastic response, followed a nonlinear region and finally graceful failure with extensive fibers pull-out. The results of stressdeflection data and SEM examination revealed that the fracture mechanism was a combination of brittle and ductile fracture. The bond strength of fiber/matrix was weak at low temperature, causing extensive fibers pull-out. On the other hand, the extent of brittle fracture of some fibers may have increased due to fiber peeling that was found to occur with each step of the ten-cycle process.

\section{ACKNOWLEDGEMENTS}

This work is supported by the Nanjing University of Aeronautics and Astronautics Fundamental Research Funds (No. NS2013061). 


\section{REFERENCES}

1. Z.F. Chen, L.T. Zhang, L.F. Cheng, Y.D. Xu and Z.H. Jin, Sci. Eng. Comp. Mater., 10, 403 (2003).

2. Y.G. Wang and J.L. Liu, Int. J. Appl. Ceramic Technol., 6, 190 (2009).

3. F.P. Meyer, G.D. Quinn and J.C. Walck, Ceram. Eng. Soc. Proc., 6, 646 (1985).

4. S. Misha, R. Mitra and M. Vijayakumar, Ceramics Int., 35, 3111 (2009).

5. C.M. Xu, S.W. Wang, X.X. Huang and J.K. Guo, Ceramics Int., 33, 669 (2007)

6. S. Han, K.H. Jiang and J.W. Tang, Adv. Mater. Res., 79-82, 1767 (2009).

7. B.B. Li, J.X. Zhu, Y. Jiang, L. Lin, Y. Liu and Z.F. Chen, Ceramics Int., 38, 2209 (2012).
8. B.B. Li, L. Lin, J. Zhu, Y. Liu and Z.F. Chen, Asian J. Chem., 25, 23 (2013). 9. K. Xu and X.W. Xu, Mater. Sci. Eng. A, 487, 400 (2008).

10. B.B. Li, L. Lin, J.X. Zhu, Y. Liu, F.D. Boafo and Z.F. Chen, Ceramics Int., 38, 4017 (2012).

11. H. Chen, L.M. Zhang, L.M. Hu, G.Y. Jia, W.H. Luo, S. Yu and Z.Q. Cheng, Key Eng. Mater., 249, 163 (2003).

12. Test Methods for Density and Specific Gravity (Relative Density) of Plastics by Displacement. ASTM Standard D792-00, American Society for Testing and Materials. West Conshohocken, PA, Vol. 81.01 (2004).

13. R.R. Naslain, Comp. A: Appl. Sci. Manuf., 29, 1145 (1998).

14. D.C. Jia, Y. Zhou and T.Q. Lei, Aerospace Mater. Technol., 31, 29 (2001) in Chinese. 